\title{
Perception of Sustainability Reporting - an Attempt by Means of Eye-Tracking
}

\author{
Thorsten Litfin \\ University of Applied Science Osnabrück, Lingen Campus, Germany \\ Gunther Meeh-Bunse \\ University of Applied Science Osnabrück, Lingen Campus, Germany \\ Katja Luer \\ University of Applied Science Osnabrück, Lingen Campus, Germany \\ Özlem Teckert \\ University of Applied Science Osnabrück, Lingen Campus, Germany
}

\begin{abstract}
Financial reporting-going back to the work of the Croatian Benedikt Kotruljević in 1458 - has been significantly developed in recent years. Notwithstanding this, financial reporting is no longer perceived as comprehensive. Large public-interest preparers as well as their suppliers have been facing pressure in their reporting: Only financial reporting together with nonfinancial reporting on Corporate Social Responsibility (CSR) is said to achieve a comprehensive view of a company's performance. Such reporting discloses amongst others social and environmental matters e.g. by means of a sustainability report. However, as there are different reporting types the goal of this paper is to identify the superior CSR reporting type from a stakeholder's perspective. After identifying and analyzing central guidelines on CSR reporting and presenting different approaches, the authors will apply positive-empirical methodology by using Eye-Tracking technology. In this first innovative joint attempt for approaching CSR quality by Eye-Tracking technology students act as subjects in order to develop hypothesis for future research after feedback from conference participants.
\end{abstract}

Keywords: sustainability reporting, quality, eye-tracking, stakeholder perception JEL classification: M14, M48

\section{Introduction}

The public call for a comprehensible Sustainability Reporting along with Financial Reporting is getting louder(see for a literature review Hahn ef al., (2013) in conjunction with Eccles et al., (2012) and Eccles et al., (2011)). The preparation of a sustainability report will become one of the major accounting challenges companies have to deal with since EU directive 2014/95/EU amending EU directive 2013/34/EU will obligate public interest companies to report on nonfinancial information (e. $\mathrm{g}$. environment, employee-related matters, future Art. 19a of the directive 2013/34/EU). The directive turns the voluntary reporting on nonfinancial information into compulsory but does not regulate how to report. Preparers keep orientating towards different initiatives on national and international level that provide various frameworks and guidelines. Based on these different frameworks and guidelines notable different reporting types were developed; there are preparers with separate sustainability reports, some prepare an embedded sustainability report and others prepare a report that uses references to the annual report, the internet presence or other already existing data. The information behavior of viewers with regard to the 
perception of CSR/Sustainability Reporting depending on the reporting type, structure and level of knowledge is hardly investigated.

\section{What is Sustainability?}

Risen from the Latin word "sustinere" (support), sustainability can be reduced to Carl von Carlowitz (1645-1714) who defined the main principle of sustainability for the area of forestry by claiming that a forest needs to be harvested in a way which ensures taking only as much wood as can grow back for future generations (Carlowitz, (1713). Today's common understanding and generally accepted definition of sustainability can be found in the Brundtland Report (United Nations, 1987): Sustainable development is development that meets the needs of the present without compromising the ability of future generations to meet their own needs. The following years the topic of sustainable development was determined as a guiding political principle. As one result the EU defined in the Treaty of Amsterdam in 1997 (European Union, 1997) an initial approach of the Three-Pillar-Model of Sustainability:

\section{- The development of Corporate Social Responsibility (CSR)}

Companies are increasingly facing new challenges along with sustainability because considering the ecological and social dimension may not have been a focus of a company's day-to-day business. The Commission of the European Communities describes the concept of CSR as a "concept whereby companies integrate social and environmental concerns in their business operations and in their interaction with stakeholders on a voluntary basis" Commission of the European Communities, 2001). So it can be emphasized that CSR includes business activities trying to fulfil a company's duty to take economic as well as ecologic and social responsibility into account.

\section{- Legal implementation of Sustainability Reporting}

To this very day unified and precise legal regulations are still missing. This is why companies refer to different, voluntary applied guidelines when it comes to reporting on CSR. On a national (German) level e.g. the German Sustainability Code provides a framework for reporting on sustainability management regardless of company size or legal form (German Sustainability Code, 2016). On an international level voluntary members of the United Nations Global Compact (UNGC) commit to take accepted sustainable principles into account - e. g. for ensuring environmental measures or protection of human rights (United Nations, 2016). Closely connected to the UNGC the guidelines provided by the Global Reporting Initiative (GRI) shall be mentioned: The guidelines include general principles and indicators to present economic, ecologic and social activities of a company transparently. As the UNGC and the GRI cooperate since May 2010, the UNGC recommends the GRI guidelines for their members, what makes them the most widespread guidelines for sustainability reporting (Global Reporting Initiative, 2016 b).

\section{- Global Reporting Initiative}

The Global Reporting Initiative was founded in 1997 with the help of the United Nations targeting methodical improvements regarding the sustainability reporting of companies (Global Reporting Initiative, 2016 a). The GRI-guidelines "G4" (fourth generation of guidelines) are currently applicable and take different levels of application into account. Especially to be emphasized is the fact that other guidelines and frameworks refer to the GRI-regulations as well what makes them also interesting for small and medium sized entities.

\section{- Sustainability reporting types}

The lack of unified and binding legal reporting guidelines leads to various sustainability reporting types; as far as the content is concerned companies are 
oriented to e.g. the GRI G4-guidelines, but they are almost free in their decision how to report:

The separate sustainability report contains only information and business figures with regard to economic, ecologic and social sustainability. This report may (partly) be based on the same database as the preparer's financial annual report, but published independent of it.

The embedded sustainability report presents information on sustainability in a separate chapter within the annual report.

The reference sustainability report uses references to already existing data and documents (e. g. the annual report) to report on sustainable business activities.

Figure 1

Reporting Types

Source: Authors' illustration

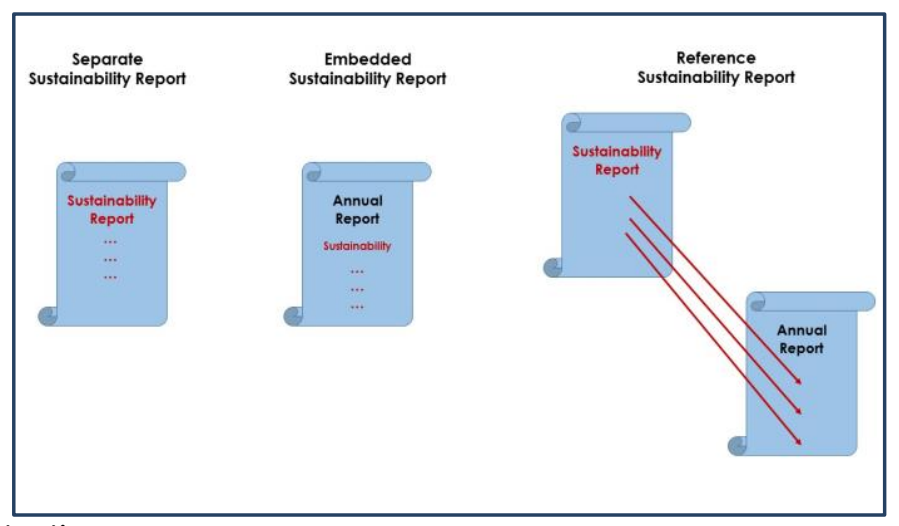

Our contribution will present the perception of the different sustainability reporting types (oriented towards GRI G4-guideliens) with the help of an eye-tracking system. Especially the mutual dependence of sustainability reporting type and the participants' information behavior takes center stage.

The results will be used determining future possible measures to improve companies' sustainability reports. Primarily it shall be analyzed whether or not particular reporting types are perceived as being especially user friendly for the general public and relevant for the perception of the enterprises' degree of sustainability.

\section{Eye Tracking}

In general, up to $90 \%$ of the perceived information is visually conveyed (Schub von Bossiazky, 1992). Yet, eye tracking provides the opportunity to capture perceptual processes with technical equipment. Eye tracking employs infrared cameras measuring where, how long and in what sequence individuals focus on specific objects. A number of empirical surveys demonstrate that the application of these instruments for the analysis of visual perceptions in the field of financial reporting is promising. The objective here was to improve the readability of those reports by increasing the visibility of key information and enhance the precision of the information. Eisl at al. (2015) provide a detailed report on the state of the art of designing company reports. These studies focus on the question of how to design tables and figures. To date there is no published eye tracking study available comparing types of sustainability reports in a holistic way.

After identifying and analyzing central guidelines on CSR reporting and presenting different approaches, the authors will apply positive-empirical methodology by using Eye-Tracking technology on the different reporting types. In order to make sensible use of Eye-Tracking technology it is combined with a paper-based survey approach. 


\section{Methodology}

The objective of this pilot study is to explore whether and to what extent the combination of an eye tracking approach with an opinion survey can deliver valuable information about the search behavior of potential stakeholders analyzing sustainability reports of companies. The following questions are of particular interest: a) does the difference in reporting types influence the search behavior of stakeholders, and b) do particular reporting types support potential stakeholders in their search for specific information and their judgment of the sustainability of companies.

Such quality of the sustainability reports/reporting types are measured by using the following questions:

- Is the preparer able to present a sustainability strategy?

- Is the structure of the sustainability report useful and clearly structured?

- Is the information content of the sustainability report (too) high or (too) low?

- Is the information provided by the preparer credible?

- Is the information provided by the preparer essential?

The participants of this exploratory study were 12 business students specialized in financial accounting. During a prior course taken by these students the focus was on sustainability reporting. The sustainability reporting of a number of companies was analyzed with the result that the participating students acquired a notable degree of expertise in this field. The underlying material for every report format in this study was a distinguished sustainability report developed by an SME with less than 250 employees. The format of their report received an award by the Institut für Ökologische Wirtschaftsforschung (Institute for Ecological Economy Research) (Gebaver et al., 2012). The study focused on SMEs in order to provide comparability and decrease the complexity for the 12 students participating in the study. The following best-practice reports have been selected: a) an embedded report by Stadtwerke Heidelberg, b) a separate report by memo AG and c) a reference report by the Märkisches Landbrot $\mathrm{GmbH}$. All reports are of high quality and have been provided to the students one week prior to the beginning of the study.

During the study the 12 students were randomly and evenly assigned to the three different reporting types. In practice, stakeholders are only interested in specific information within a sustainability report. In order to simulate these particular interests each of the students received specific questions for the criteria associated with the three dimensions of sustainability. A pretest conducted with three members of staff revealed a lack of time to answer all questions. For this reason the time allocated was increased from previously planned 10 to 20 minutes. The type of questions and tasks, proofed comprehensible and traceable.

The mobile eye tracking system 'Tobii Pro Glasses 2', enabling the actimetry and analysis of individual gaze behavior was employed for the documentation of the search and response behavior of the 12 students. In order to assess the quality of responses in relationship to the three criteria and the search behavior of the students, an expert for CSR applied a one-to-five order Likert scale. In order to detect whether the search behavior correlates with the judgment of sustainability reports, students were asked to: 1) participate in the eye tracking test, 2) judge the sustainability reports according to the available criteria, and 3) express an overall judgment. Here, the Likert scale was applied for purposes of consistency. 


\section{Results}

The applied methodology was successful in terms of reconstructing and analyzing the search and information browsing behavior of the 12 students. With the exception of one individual, all students used the table contents as a reference after a short period of orientation. This means the search behavior may be referred to as targeted. In order to determine the fixation duration on the table of contents or the index the eye-tracking data collected were automatically mapped onto these areas of interest (AOI) by using snapshots of the relevant page. These fixation durations are listed in Table 1.

\section{Table 1}

Time of Interest Fixation Duration (Page including Contents)

\begin{tabular}{|c|c|c|c|c|c|c|}
\hline & \multicolumn{6}{|c|}{ Type of Sustainability Report } \\
\hline & \multicolumn{2}{|c|}{ Reference } & \multicolumn{2}{|c|}{ Embedded } & \multicolumn{2}{|c|}{ Separate } \\
\hline & Avg. & $\underline{S D}$ & Avg. & $\underline{S D}$ & Avg. & $\underline{S D}$ \\
\hline $\begin{array}{l}\text { Total time of interest } \\
\text { Duration } \\
\text { in seconds }\end{array}$ & 268.56 & 55.09 & 64.49 & 15.86 & $\begin{array}{l}286.44 \\
100.03^{*}\end{array}$ & $\begin{array}{l}97.03 \\
12.56^{*}\end{array}$ \\
\hline$\%$ of total recording & 22.22 & 4.53 & 6.08 & 1.39 & $\begin{array}{l}27.19 \\
10.24^{*}\end{array}$ & $\begin{array}{l}4.98 \\
2.20^{*}\end{array}$ \\
\hline
\end{tabular}

*Note: The upper figure provides the fixation durations of an entire page, whereas the lower figure lists the fixation duration of the table of contents.

The table of contents of the embedded report was analyzed in the shortest period of time both in relative and absolute terms in comparison with the entire recording period. The separate report has additional information and a figure placed next to the table of contents. For this reason the table of contents was defined as additional AOI. Taking into account an adjusted fixation duration of the table of contents the overall duration of the reference report is significantly longer than the other two reports. The heat maps as displayed in Figure 2 reveal which elements are most intensely observed. The attention map of the separate report shows that most of the visual attention is directed towards the figure which distracts the viewer from the table of contents. In comparison to the duration of the entire page the table of contents attracted only $40.6 \%$ of it. The analysis of the reference report reveals a wide scattering of the fixation. In contrast, the embedded report shows an aggregation of fixation.

Figure 2

Heat maps of pages including their contents (absolute duration)

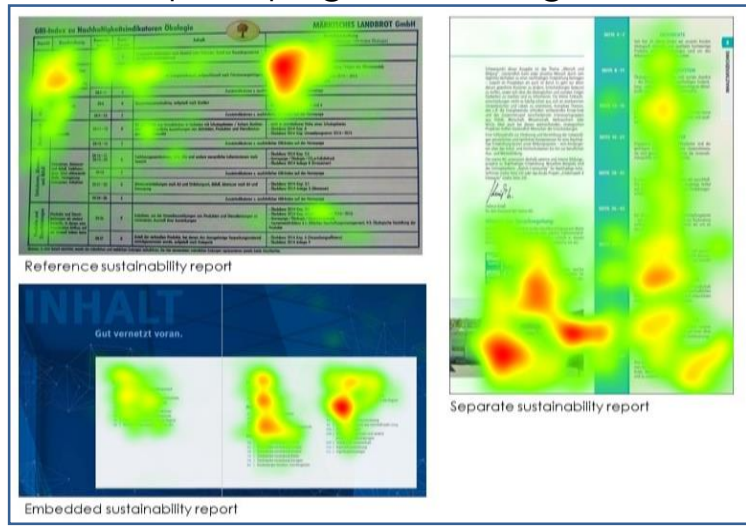

*Note: Absolute duration is calculated by the duration of fixations, whereas the warmest color represents the highest value. 
The sustainability ratios of the embedded report are consolidated over four consecutive pages. The focus here is on environmental protection, labor force and the company's regional commitment. The sustainability dimensions 'social' and 'ecology' are bundled. The students remained on those four (of 116 ) pages for $35 \%$ of the recorded time.

Table 2

Evaluated response and perceived reporting quality

\begin{tabular}{|c|c|c|c|c|c|c|c|}
\hline & & \multicolumn{6}{|c|}{ Type of Sustainability Report } \\
\hline & & \multicolumn{2}{|c|}{ Reference } & \multicolumn{2}{|c|}{ Embedded } & \multicolumn{2}{|c|}{ Separate } \\
\hline & & Avg. & $\underline{S D}$ & Avg. & $\underline{S D}$ & Avg. & $\underline{S D}$ \\
\hline \multirow{4}{*}{$\begin{array}{l}\text { Evaluation of the } \\
\text { response quality of } \\
\text { the questions (eye } \\
\text { tracking-study) }\end{array}$} & Ecology & 3.25 & $\overline{1.48}$ & 5.00 & $\overline{0.00}$ & 5.00 & $\overline{0.00}$ \\
\hline & Economy & 2.25 & 1.64 & 4.00 & 0.00 & 4.50 & 0.87 \\
\hline & Social & 3.00 & 0.00 & 5.00 & 0.00 & 4.00 & 1.00 \\
\hline & Regional & 2.50 & 0.50 & 4.00 & 0.71 & 1.50 & 0.87 \\
\hline \multicolumn{8}{|c|}{ Subsequent assessment of the sustainability report } \\
\hline \multirow{5}{*}{$\begin{array}{l}\text { Perceived reporting } \\
\text { quality }\end{array}$} & Sustainability strategy & 2.00 & 0.00 & 3.00 & 0.71 & 3.50 & 0.50 \\
\hline & Structure & 1.50 & 0.50 & 4.00 & 0.71 & 3.75 & 1.09 \\
\hline & Information content & 3.50 & 0.50 & 3.75 & 0.43 & 3.75 & 0.43 \\
\hline & Credibility & 4.50 & 0.50 & 4.00 & 0.71 & 3.75 & 0.83 \\
\hline & Essentiality & 2.50 & 0.50 & 3.25 & 0.43 & 3.25 & 1.09 \\
\hline \multirow{3}{*}{$\begin{array}{l}\text { Assessment of } \\
\text { sustainability }\end{array}$} & Economic & 4.00 & 0.00 & 2.25 & 0.43 & 2.75 & 0.83 \\
\hline & Ecology & 3.75 & 1.09 & 3.75 & 0.43 & 3.75 & 0.83 \\
\hline & Social & 4.00 & 1.22 & 3.50 & 1.12 & 3.50 & 0.87 \\
\hline CSR idea & & 4.25 & 0.83 & 3.50 & 0.50 & 3.50 & 0.50 \\
\hline
\end{tabular}

Note: Likert scale where 1= very poor; 5 = very good

While the four students of the embedded report were able to entirely answer the questions in the sequence provided, the students of the other two groups responded unsystematically, with no recognizable pattern and partly incomplete. In spite of the explicit focusing (table 2) the analysis of responses of the embedded report group resulted in high quality responses. The separate report group performed almost as well as the embedded group. In contrast, the reference report group was just rated as having satisfactory results.

The analysis of perceived reporting quality by the students resulted in comparable grades as the results of the embedded and the separate report groups are on the same level as the analysis of duration fixations. However, the reporting structure and the sustainability strategy of the reference report are not convincing. This is in contradiction to the credibility and the application of the CSR idea.

\section{Discussion}

The analysis of the eye tracking study demonstrated that tables of contents play a significant role in the orientation of the viewer. A search begins with the Table of contents that also guides the viewer decisively. This enhances the identification of relevant information. The analysis of the page with the table of contents in the separate report revealed that figures and miscellaneous information on the same page distract from the relevant contents since they attract much of the visual attention. According to our results a table of contents requires a distinct page in order to enhance the orientation of a viewer.

In the reference report references were distributed over three pages according to the GRI index for sustainability dimensions, 'economy', 'ecology' and 'social'. The students rated the structure of this report more negatively than the other groups. In addition, the students showed more uncertainty in their search behavior and had 
more difficulty in responding to the questions on the reference report. The reasons for this may be the reference structure on the one hand and the scattering of information over several pages on the other. As a consequence, the quality of responses to this report was remarkably lower in comparison with the other two reports. Moreover, the students became frustrated while processing the questions, and they expressed their dissatisfaction with this task. Our findings indicate that the report type "reference sustainability report" may not be advisable.

In contrast, it was easier for the students to respond to the questions for the embedded report. They evaluated the reporting structure positively, and at the same time delivered answers of higher quality. The reason may be the condensed representation of sustainability figures in a low number of pages. This study supports the trend towards the application of an embedded sustainability report in practice as postulated e.g. by Hahn et al. (2013).

\section{Conclusion}

This pilot study of a combined eye tracking and survey approach demonstrated the validity of this methodology for the analysis of search and information browsing behavior in various types of sustainability reports. Thus, empirical research towards the enhancement of the readability does not need to be constraint to the design of tables and figures (Eisl et al., 2015), but may examine the visual perception and the resulting assessment of sustainability reports in a holistic way. Notwithstanding this our study faced limitations. These are in particular types and numbers of students, the not mapped heterogeneity of real-world stakeholders and drawing on reports of different business fields. Subsequent studies should try to overcome these limitations. Subjects might be recruited from various vocations such as investors, clients, nongovernmental organizations and employees. In future studies three reporting types may be applied to one enterprise. In ideal the results would permit a direct conclusion about the reporting type that is the superior information provider to stakeholders.

\section{References}

1. Carlowitz, H. C. (1713), Sylvicultura Oeconomica, oder hauswirthliche Nachricht und naturmässige Anweisung zur wilden Baumzucht, published by Johann Friedrich Braun, Leipzig.

2. Commission of the European Communities (2001), "GREEN PAPER: Promoting a European framework for Corporate Social Responsibility", available at: http://europa.eu/rapid/press-release_DOC-01-9_en.pdf (22 April 2016).

3. Eccles, R. G., Krzus, M. P., Rogers, J., Serafeim, G. (2012), "The Need for Sector-Specific Materiality and Sustainability Reporting Standards", Journal of Applied Corporate Finance, Vol. 24 No. 2, pp. 65-71.

4. Eccles, R. G., Krzus, M. P., Serafeim, G. (2011), "Market Interest in Nonfinancial Information", Journal of Applied Corporate Finance, Vol. 23 No. 4, pp. 113-127.

5. Eisl, C., Falschlunger, L., Hofer, P., Jungert, M. (2013), "Reporting Design - A Systematic Literature Review", ACRN Journal of Finance and Risk Perspectives, Vol. 2 No. 2, pp. 27-47.

6. Eisl, C., Losbichler, H., Falschlunger, L., Grabmann, E., Hofer, D. (2015): "Information Design in Company Report of Dax 30-Companies: An Empircal Investigation of University of Applied Sciences Oberösterreich and of KPMG", available at: https://www.kpmg.com/DE/de/Documents/information-design-geschaeftsberichtedax-30-unternehmen-2015-kpmg.pdf (4/26/2016). 
7. European Union (1997), "Treaty of Amsterdam amending the Treaty on European Union, the Treaties establishing the European Communities and certain related acts". Available at:

http://europa.eu/eu-law/decisionmaking/treaties/pdf/treaty_of_amsterdam/treaty_of_amsterdam_en.pdf (4/22/2016).

8. Gebaver, J., Westermann, U. (2012), "IÖW/future Ranking of Sustainability Reports of German Small and Medium Sized Companies: Results and Trends", Berlin, Münster: http://www.rankingnachhaltigkeitsberichte.de/data/ranking/user_upload/pdf/lOEWfuture-Ranking_2011_KMU_Ergebnisbericht.pdf (4/26/2016).

9. German Sustainability Code (2016), "Information for users", available at: http://www.deutscher-nachhaltigkeitskodex.de/en/application/information-forusers.html (4/22/2016).

10. Global Reporting Initiative (2016a), "About GRI", available at: https://www.globalreporting.org/information/news-and-press-center/pressresources/Pages/default.aspx (4/22/2016).

11. Global Reporting Initiative (2016b), "United Nations Global Compact", available at: https://www.globalreporting.org/information/about-gri/alliances-andsynergies/Pages/United-Nations-Global-Compact.aspx (4/22/2016).

12. Hahn, R., Kühnen, M. (2013), "Determinants of sustainability reporting: a review of results, trends, theory and opportunities in an expanding field of research", Journal of Cleaner Production, Vol. 59, pp. 5-21.

13. Schub von Bossiazky, G. (1992), "Psychologische Marketingforschung", Vahlen, München.

14. United Nations (1987), "Our common Future", available at: http://www.undocuments.net/ocf-02.htm (4/22/2016).

15. United Nations (2016), "What is UN Global Compact?". Available at: https://www.unglobalcompact.org/what-is-gc (4/22/2016).

16. World Commission on Environment and Development (1983)," Our common future", available at: http://www.un-documents.net/ocf-02.htm (4/22/2016).

\section{About the authors}

Prof. Dr. Thorsten Litfin is a Full Professor at University of Applied Sciences Osnabrueck - Campus Lingen. The author can be contacted at t.litfin@hs-osnabrueck.de.

Prof. Dr. Gunther Meeh-Bunse is a Full Professor at University of Applied Sciences Osnabrueck - Campus Lingen. The author can be contacted at g.meeh-bunse@hsosnabrueck.de.

Katja Luer, LL.M., is Research Assistant at University of Applied Sciences Osnabrueck Campus Lingen. The author can be contacted at k.luer@hs-osnabrueck.de.

Özlem Teckert, M.A., is Research Assistant at University of Applied Sciences Osnabrueck - Campus Lingen. The author can be contacted at o.teckert@hsosnabrueck.de. 